\title{
THE REAL, THE APPARENT, AND WHAT IS eigentlich
}

\author{
REGINE ECKARDT \\ University of Göttingen
}

\section{ABSTRACT}

In this paper, I will propose a uniform analysis for adjectival and certain instances of adverbial eigentlich. The analysis rests on the assumption that eigentlich contrasts the nominal content of a concept $C$ with a contextually given notion of phenomenological evidence for $C$-hood. eigentlich offers the semantic frame to refer to two ways of $C$-hood which are usually supplied by context. In the adjectival use, the discourse content should provide an $N$ exemplar in the true sense (an eigentliches $N$ ) along with an apparent $N$, thereby proving the two notions to be different. In the adverbial use, the message conveyed is usually that the actual world nominally satisfies some proposition $p$ (eigentlich, $p$ ) while the actual world looks as if a contrasting proposition $q$ were the case. The analysis improves on earlier accounts in German descriptive linguistics in that it offers a fully compositional account of the semantic and pragmatic contribution of eigentlich in a wide variety of constructions, including focus, contrastive topic and questions. The analysis proposes a delineation of eigentlich as an emotive marker which differs from the content use in prosody, syntax, focus sensitivity and meaning.

\section{[1] D A T A}

The German word eigentlich can be used in a range of contexts, with meanings and implications that are hard to delimit. Linguists' interest was first drawn to eigentlich as a discourse particle, like in (1) (where eigentlich is to be read without accent). Its contribution is hard to translate into English in such examples, and it is equally difficult for native speakers of German to define or paraphrase the meaning of the word.

(1) a. Was willst Du eigentlich hier? what want you eigentlich here

[*] This paper is a substantially revised version of Eckardt (2006), presented at the Oslo SPRIK Colloquium in 2006. Due to valuable comments of two anonymous reviewers, the analysis in the present paper differs substantially from the one proposed there. My eigentlich project rests on joint work with Angelika Port whom I need to thank for many insightful criticisms and her continuous challenge with real data. All unclarities and faults in the analysis are in my responsibility. 
'what do you want here after all / at all / anyway / ... thinking about it'

b. Da hast $\mathrm{Du}$ eigentlich recht. there have you eigentlich right 'You are right after all / thinking about it / to tell the truth'

We will approach these uses indirectly, via the meaning of the intuitively more contentful, more graspable stressed adjectival and adverbial use. Let me start by listing some of the facts about the use of eigentlich. The sentences in (2) offer some examples for adjectival eigentlich, which typically, but not exclusively, occurs with an accent. Small caps indicate accents.

(2) a. Der EIGENTLiChe Chef ist verreist.

'the real boss is on a trip'

b. Der EIGENTLiche Mörder war Smith.

'the actual murderer was Smith'

c. Das EIgentliche Problem ist seine Faulheit.

'the essential problem is his laziness'

The English translations illustrate the possible range of paraphrases. Given that there is no single translation that would match all uses, a precise semantic analysis might even be of practical interest. I will use eig to stand in for eigentlich in translations and glosses. Another fact about eigentlich is that the adjective cannot occur in predicative use. Hence, examples like in (3) are all ungrammatical.
a. *Das Problem war eigentlich.
*the problem was eig
b. *Der Mörder wurde eigentlich.
*the murderer became eig

Moreover, there is no antonym to eigentlich that can be morphologically derived in a transparent way. Isolated exceptions can be found in expert languages where eigentlich has a specific, theory-internal meaning. (4-b) lists examples.
a. *Das ist ein / der uneigentliche Garten. this is a / the un-eig garden
b. un-eigentliches Integral (mathematics), un-eigentliches Kompositum (linguistics)

One striking observation about eigentlich is a definiteness effect. In positive contexts, it can only be used in definite NPs. Indefinite uses are restricted to negative contexts, like in (6) (few or rarely cannot license indefinite + eigentlich), and quan- 
tificational uses like in (7) are not allowed in Standard High German. ${ }^{1}$

(5) a. Der eigentliche Chef kommt nur dienstags. 'the eig boss only comes on Tuesdays'

b. Die eigentlichen Bewohner sind gerade verreist. 'the eig inhabitants are just away'

'The real inhabitants are presently on a trip'

c. *Ein eigentlicher Chef kommt nur dienstags. 'an eig boss ...' (even if there are several bosses.)

d. *Ein eigentlicher Bewohner hat gerade das Haus verlassen. 'an eig inhabitant ...'

(6) a. Ein eigentlicher Vertrag wurde nicht abgeschlossen. 'there was not made any eig contract'

b. Niemand hatte einen eigentlichen Lösungsvorschlag. 'no one had any eig proposal how to solve the problem'

(7) a. *Die meisten eigentlichen Stadträte wohnen im Süden. 'most eig senators live in the South'

b. *Einige eigentliche Spieler traten am Samstag an. 'some eig players came on Saturday'

Complex nouns of the form 'eigentliche $(r / s) N$ ' share definiteness effects of superlatives. There seems to be a notion that the individual that is the eigentliche $N$ is a unique (single or plural) individual. In section 3, I will take a closer look at the semantic rationale that could motivate this fact about the use of eigentlich.

Finally, there is a strong tendency to use eigentlich in the sense of true / real / actual / essential with a stress. Stressed uses will invariably express a semantic contribution in one of these senses. This sets eigentlich apart from ordinary adjectives or adverbs where pitch accent and meaning are usually independent. Earlier authors have suggested that the stress on eigentlich has some kind of motivation (see Frühwirth 1999). They propose that some kind of contrast is evoked without, however, offering any concise analysis of the prosodic facts. An analysis should also allow for rare unstressed adjectival uses like in (8).

(8) Der eigentliche ChARme an der Sache ist aber, daß GM die Renovierung auch noch zahlt.

'the eig TRICK about the thing is, however, that GM will even pay for the renovations'

[1] GOOGLE searched data show convincingly that rare positive hits of the kind in (7) offer clear evidence for an interesting dialectal variation between Standard German and Swiss German. 
The example in (8) (a real online quotation) did not contrast the true trick with other, minor advantages of some plan. Most examples, however, and certainly those that I have listed so far, will occur most naturally in a discourse where eigentliches $N$ contrasts with objects or persons that are not real Ns even though you might think so. The above examples should be read with the following trends and generalizations:

- If eigentlich occurs in positive definite contexts, it is most naturally read with a pitch accent. Presented with this accent pattern, hearers/readers will reconstruct a suitable preceding discourse where the eigentliche $N$ is contrasted with something else. We will take a closer look at the nature of this contrast in section 3 .

- In negative contexts, as in (6), eigentlich needs no accent.

- In an example like (8), eigentlich carries no stress. Nevertheless, the use of eigentlich suggests a contrast to other things - in the example, other positive aspects about the renovations - even though these may not have been explicitely listed in the actual text. (If you remove eigentlich in (8), the resulting sentence suggests that the payments are the one and only charming aspect of the renovation plan.)

So far, we have restricted attention to adjectival eigentlich. In the adverbial use, the role of accent is even more important. The presence or absence of the accent makes a clear distinction between uses in a sense that closely corresponds to truly, really, in fact, and the discourse particle use. This latter use is intuitively different, as the paraphrases in (9) illustrate.
a. Wie heißen Sie eIgENTLICH?
'what is your real name?'
b. Wie HEISSEN Sie eigentlich?
'what's your name, by the way?'

It is all the more necessary to understand the role of accenting, literal contribution and pragmatic effects of adverbial eigentlich. In delimitating the semantic analysis of eigentlich, I will proceed from clearer to more sophisticated cases. I will start by devising a semantics for the uses of adjectival eigentlich, including an analysis for the accent pattern. I will propose an account for unstressed adjectival uses in positive and negative contexts. Finally, stressed adjectival uses will be analyzed in their semantic and pragmatic dimensions. Against this background, I will turn to adverbial unstressed eigentlich, which serves to annotate an utterance with a certain speaker attitude. It can be hypothesized how this use arose as a generalization of side messages of stressed eigentlich. In view of a very nicely 
working semantic analysis of stressable eigentlich, I will propose that adverbial unstressed eigentlich belongs to the category of discourse particles, and should be distinguished from stressable eigentlich.

\section{[2] EARLIER ANALYSES}

A wide range of authors have approached the meaning and use of eigentlich from a descriptive perspective in German linguistics. While I will not review all these in detail, there are several main issues that delineate different positions in this debate.

(i) Are there one or two homophonous adverbial eigentlich?

(ii) Does its effect lie in weakening or strengthening the assertion?

(iii) What is the role of its contrasting function?

(iv) In questions: Does it always convey casualness, friendliness?

The most important question is whether we should distinguish adverbial eigentlich from a homophonous discourse marker. Intuitively, it seems clear that two opposed uses should be distinguished, differing in grammatical as well as semantic properties. On the one hand, we find discourse particle uses of eigentlich where nothing except a certain "flavor" is added to the assertion. Diagnoses vary as to what the exact nature of this flavor should be, but it seems hard to give any clear paraphrase (or English translation). (10) offers an example.

(10) Ich mag ihn eigentlich.

I like him eig

'thinking about it a bit, I'd say that I like him in fact'.

Such uses usually occur sentence internal or final. Eigentlich is not stressed. On the other hand, we also find eigentlich in stressed uses, and in topic positions, two features that discourse markers do not normally allow (see Meibauer 1994). Such uses moreover convey a more graspable message, something like "in truth", "in actual fact", "really".

$$
\begin{aligned}
& \text { EIGENTLich heisse ich Max. } \\
& \text { eig be-called I Max } \\
& \text { 'It's true, my name is Max' }
\end{aligned}
$$

Even though no author so far could define a clear demarcation between uses like in (10) and uses like in (11), the poles of the continuum of usages are distinct enough to warrant an ambiguity debate. However, only those few who are interested in a formal semantic analysis (notably Schmitz and Schröder 2004; Schmitz 
2008) adopt the assumption of a "discourse particle" at one end and the conceptually richer adverb at the other

A majority of authors (Weydt 1977; Thurmair 1989; Frühwirth 1999) however assume that only one entry eigentlich is sufficient. They point out that the proposed grammatical properties of discourse markers (in Meibauer 1994) should be seen as prototypical features rather than necessary properties. According to these authors, eigentlich with a pitch accent, and in topic position, like in (11), could still be a discourse marker in the sense of Meibauer's classification. Their main point in favor of a single lexical item eigentlich is parsimony in semantic modeling. They point out that all uses of eigentlich rest on one common underlying semantic core (without, however, specifying that core clearly). In addition, they stress that no morpho-phonological dissociations can be traced that would support two different lexical entries.

Let us address the speculations about the semantic core of eigentlich in some more detail. Most traditional approaches characterize the contribution of eigentlich in terms of "weakening" or "strengthening" the assertion. This is puzzling not only in that it remains unclear in what sense an assertion can be strengthened or weakened. It is also puzzling in that different authors (and sometimes even one and the same) diagnose eigentlich as both weakening and strengthening. I will offer two examples, both quoted after Frühwirth (1999), which have been categorized as a "weakening" and a "strengthening" use respectively, without further attempts at spelling out the intuition.

(12) EIGENTLICH habe ich keine Zeit. ("weakening", discussed in Kohrt 1988) Eig have I no time

(13) Gehst Du heute Abend mit ins Training? - Ich habe eigentlich keine Zeit. 'Will you join me to go to training tonight? - I have eig no time' ("strengthening", discussed in Weydt and Hentschel 1983)

These apparently conflicting diagnoses in terms of traditional grammar do not add to our understanding of the meaning of the term, and urgently require elucidation.

A further observation concerns the relation between an eigentlich sentence and its local discourse context. Frequently, the sentence is contrasted with a preceding or following utterance. Frühwirth offers examples like the following.

(14) Ich hasse Oliven. Naja, eigentlich mag ich sie nur nicht besonders gerne. 'I hate olives. Oh well, in fact I just don't like them very much.'

(15) Ja, aber eigentlich kam es mir nicht nur so vor! Ich war es tatsächlich! 'Yeah, but in fact it not just seemed to be like that. I really was it.'

(16) Obwohl es sehr belastend war, hat mich die Wiedervereinigung eigentlich 
gefreut.

Although it was very depressing, the reunification eig made me happy

The contrasting function of eigentlich is unanimously acknowledged by authors. It is at the basis of the only formal approach to the contribution of eigentlich that seems to exist to date, the analysis by Schmitz and Schröder (2004). They assume that eigentlich serves to block some default inference that the listener would otherwise derive from the sentence. The sentence in (17) the prime example in their paper.

Eigentlich geht Ostwind. Aber es regnet.

'Eigentlich is an easterly wind. But it's raining.'

Schmitz and Schröder observe that the assertion "there is an easterly wind" will give rise to the default expectation (in the meteorological context of Germany) that the weather is dry. In (17) 'there is an easterly wind' warrants the default inference: 'the weather is sunny' (in a central German climate). The function of eigentlich lies in signaling that this non-monotonic inference should be blocked. The following sentence asserts a proposition that is in conflict with this default inference. The authors offer a very elegant implementation of this idea in terms of update semantics.

Schmitz and Schröder in fact capture an essential insight about the use of eigentlich. The analysis leads to very reasonable predictions in many examples. However, for the sake of a unified semantic analysis the authors disregard both the adjectival use as well as the question whether an extra discourse marking function must be acknowledged. The latter seems the more serious omission. Examples like (18) show that not all uses of eigentlich block default inferences:
a. Sollen wir zum Frühstück einen Sekt
aufmachen?
Shall we for breakfast a
Champagne open?
b. (hesitating)Ach - heute ist ja
eigentlich Sonntag! Gut,
Ach - today is PARTICLE eig
Sunday. Well,
machen wir das.
let's do so.
'Should we have Champagne for breakfast? - I don't know ... well, yes, after all, it's Sunday. Let's have some.'
You have eig right
'You are right after all.'

(19) Du hast eigentlich recht.

In (18), speaker B first contemplates the negative consequences of having champagne so early in the morning - first, its fun, but afterwards one is tired, one 
wants to take a nap, or one can not work properly. Yet, he then comes across a fact that might still support A's suggestion: After all, it's Sunday. So, let us behave accordingly. In this example, no default inference of "it is Sunday" seems to be withdrawn. On the contrary, if any default plays a role here, it is "Sundays are lazy days" which is supported, not blocked, in this context. Likewise, an utterance like (19) is used normally to convey agreement-after-some-reflection. The speaker states that the hearer is right. And that one should act, behave, or decide accordingly. I will in the following label such examples as the "let's act accordingly", or pensive use of eigentlich. In later sections, it will be argued that this distinction corresponds to the following:

a. adv. eigentlich: in association with focus; operator on properties; stressed; related to adjectival eigentlich; in questions: operates on questioned property.

b. mp eigentlich: unstressed; speech act signal; no relation to focus; no transparent relation to adjectival eigentlich; let's act accordingly uses, pensiveness; in questions: adds the 'after some reflection' flavor

At the present point, the data simply show that Schmitz and Schröder's uniform analysis of adverbial eigentlich does not as yet cover all data, and that the analysis moreover does not offer any clue as to how the prosody and word order facts of examples can be turned into a prediction about the nature of the examples in question. Do they represent an eigentlich - but use (i.e. in line with their analysis) or an eigentlich - let's act accordingly use (and hence unpredicted). Importantly, Schmitz and Schröder acknowledge an extra discourse marking use in questions like (20)

$$
\begin{aligned}
& \text { Wie heißen Sie eigentlich? } \\
& \text { How are-named you eig? } \\
& \text { 'what's your name, by the way?' }
\end{aligned}
$$

They briefly characterize the function of eigentlich as marking a casual, friendly question. I will come back to this claim when we deal with the discourse marking function of eigentlich.

\section{[3] SEMANTICS AND PRAGMATICS OF ADJECTIVAL eigentlich}

An appropriate analysis of adjectival eigentlich should explain the definiteness effects, the fact that the adjective is non-intersective, its preference for pitch accent as well as the contrastive function that has been repeatedly observed in grammars, dictionaries and the literature. Let us take a closer look at this function, which 
constitutes the core contribution of the word. ${ }^{2}$ In all cases, there is a feeling that the speaker wants to contrast the "real stuff" to something which, even though it might look similar, is not the "real stuff". So, example (2.c) refers to das eigentliche Problem (= 'the eig problem') and suggests that other facts in the given context could constitute 'minor problems'.

Examples like (2.a) and (2.b) are similar, though slightly different. If one calls someone the eigentliche Mörder ('eig murderer'), one rarely refers to circumstances where more persons hurt the victim in minor ways. Usually, the speaker refers to hypothetical or apparent murderers, persons which were for some time hypothesized to be murderers but turned out not to be. The opposite of eigentlicher Mörder hence is scheinbarer (apparent, seeming) Mörder. Comparing the meaning of Mörder and eigentlicher Mörder, it turns out that the two are co-extensional. Murderers are true murderers, and one cannot more truly kill someone than by being a murderer (eigentlich or not).

$$
\text { [eigentlich }+ \text { murderer } \rrbracket=\llbracket \text { murderer } \rrbracket
$$

Similar observations hold for Chef and eigentlicher Chef (= boss). Persons may be mistaken as being the 'boss' but reference to eigentlicher Chef suggests that from that point on, no such "substitute" bosses should be called Chef.

The following classical quote in Adelung (1774, taken from Schmitz and Schröder $2004,12)$, in turn, suggests that sometimes the speaker wants to distinguish between a "nominal" extension of the noun in contrast to the "true" extension of the noun, which is a subset of the former.

(22) Das eigentliche Griechenland, derjenige Theil Griechenlands, the true/real Greece, that part-of Greece welchem dieser Name der schärfsten Wahrheit nach zukommt. to-which this name the sharpest truth acoording-to belongs 'the true/real Greece, that part of Greece that most truly deserves that name'

If we imagine the geographical map of Greece, we can delineate those parts that count as the "true, real" extension of Greece. Everything outside is "Greeceunder-a weaker-standard", "parts that were erroneously taken to belong to Greece", or similar hedges. The resulting picture reflects nicely what we assume to be the semantic contribution of eigentlich. It is used to cut a property's extension down to the true core.

I propose that eigentlich generally leads from a property concept $C$ to two further semantic objects: the 'nominal' notion of 'being a $C$ ' as contrasted to the

[2] Throughout this section, eigentlich will always be the adjective. I omitt this qualification to ease readability. 
phenomenological notion of 'being a $C$ '. More specifically, the phenomenological notion usually is tied to a set of typical properties that would allow subjects to identify an object as 'being a $C$ '. I will use $\operatorname{PHÄN}(C)$ and Noм $(C)$ to refer to the two sets of properties.

Let $\mathrm{N}$ be a noun and $C$ be the property denoted by that noun. Moreover, assume that $\mathrm{N}$ is used in an utterance situation $\mathrm{s}$.

$\operatorname{Nom}(C)=\left\{N_{1}, N_{2} \ldots\right\}$ the set of property concepts that define the extension of $\mathrm{N}$. In the normal case, this can be just $C$; in some cases the speaker intends to cut down $C$ to a subset of $C$.

$\mathrm{PHÄN}_{\mathrm{H}}(\mathrm{C})=\left\{\mathrm{P}_{1}, \mathrm{P}_{2} \ldots\right\}$ a set of property concepts that the speaker in $s$ presents as the typical phenomenological evidence to classify an object as having $C$. Good paraphrases could be "what a $C$ object usually looks/is/behaves like". Note that there need not be a unique set PHÄN $(C)$ tied to $C$. What is perceived as typical for $C$ can vary from utterance situation to utterance situation.

These two sets of properties are at the basis of adjectival eigentlich and will later serve as the basis to reconstruct Schmitz and Schröder's observation about blocked default inferences in terms of a truth conditional setup. Before turning to the semantic analysis of the complex phrase \eigentlich $N \rrbracket$, we will have to check the contribution of eigentlich in referring to a set of objects related to $N$. Interestingly, eigentliche $N$ can be used in two senses: In one kind of use, the speaker wants to refer to the nominal core of $N$. In this case, the overall referent of the NP 'Det eigentlich (e) $N$ ' is characterized as being $N$ in the 'nominal' sense, and not just looking like an $N$. In another kind of use, however, the speaker wants to present the referent of 'Det eigentlich(e) $N$ ' as exhibiting all typical features of $N$ even though it is not in the actual extension of $N$ in the 'nominal' sense. ${ }^{3}$ The two following examples illustrate the two usages.

(24) Frau Meier leitet die Geschäfte von Tag zu Tag. Die EIgEnTliche Mrs. Meier leads the business from day to day. The eig Chefin ist Frau Schmitz.

boss is Mrs. Schmitz.

'Mrs. Meier makes the day-to-day business decisions. The true boss is Mrs. Schmitz.'

(25) Frau Schmitz steht der Firma offiziell vor. Die EIGENTLICHE Mrs. Schmitz stands the company officially before. The eig

[3] I want to thank an anonymous reviewer for pointing out this really crucial observation on the two kinds of usages of eigentlich. 
Chefin ist aber unsere Sekretärin, Frau Meier.

boss is however our secretary, Mrs. Meier.

'Mrs. Schmitz is the official leader of the company. The true boss, however, is our secretary Mrs. Meier.'

Let me go through the rationale behind these two examples. Sentence (24) states that

- Mrs. M fulfills functions which are phenomenologically tied to the notion be the boss like taking decisions, leading business, etc.

- Mrs. $\mathrm{S}$ is the boss in the 'nominal' sense (for instance, in legal respects).

- Mrs. S is the eigentliche Chef.

Sentence (25) contrasts the same two ways in which people can be boss using eigentlich in the opposite direction:

- Mrs. $\mathrm{S}$ is the boss in the 'nominal' sense (for instance, in legal respects).

- Mrs. M fulfills functions which are phenomenologically tied to the notion be the boss like taking decisions, leading business etc.

- Mrs. M is the eigentliche Chef.

This twin pair of examples can be systematically multiplied. It shows that adjectival eigentlich can not be analyzed as always leading from look-like $N$ to actual $N$. Neither does it always serve to lead from $N$-by-name to $N$-by-typical-property. However, it systematically serves to point out that this difference exists and that $\mathrm{N}$-by-nameand $\mathrm{N}$-by-typical-property have different extensions. This is likewise exemplified in (24)/(25) The little sample discourses contain referents which show the difference between $\mathrm{N}$-by-name and $\mathrm{N}$-by-typical-property. In our example, the extensions of Chefin-by-name and Chefin-by-function are singletons, and the speaker states that the two singleton sets differ. In other cases, it can be sufficient to state that some referent is in the extension of one property, but not the other. This option is exemplified in the adverbial uses (see below).

The definition in (23) introduced two sets of properties that are tied to a concept $C$. In the discussion of $(24) /(25)$, I have repeatedly referred to properties simpliciter that are exhibited by some individual. I will now turn to a definition that leads from a set of properties to the mereological sum of these. This sum will be a unique mereological object (or, intension thereof) which will explain the definiteness effects that were stated at the outset of the paper. The definition is stated in terms of an analysis of properties in two-sorted type theory. Moreover, we assume that properties are attributed to singular and plural objects that are 
mereologically ordered by a relation $\leq$. For details, the reader is referred to Link (1983) or other introductions to plural ontologies. It should, however, be possible to follow the subsequent discussion on basis of an intuitive understanding of the formal details.

(26) Let $\left\{\mathrm{P}_{1}, \mathrm{P}_{2} \ldots \mathrm{P}_{\mathrm{n}}\right.$ be a set of property concepts of type (s,(e,t)). Let the domain of objects be mereologically ordered $\leq$. Let SuP $(\mathrm{X})$ be the supremum object of a subset $\mathrm{X}$ of the domain of entities. The sum of the properties is defined as

$\sum\left\{\mathrm{P}_{1}, \mathrm{P}_{2} \ldots \mathrm{P}_{\mathrm{n}}\right\}:=\lambda w \lambda \mathrm{Z}\left[\mathrm{Z}=\operatorname{SuP}\left(\left\{\mathrm{P}_{1}(w), \mathrm{P}_{2}(w) \ldots \mathrm{P}_{\mathrm{n}}(w)\right\}\right)\right]$

Note that in each possible world $w, \sum\left\{\mathrm{P}_{1}, \mathrm{P}_{2} \ldots \mathrm{P}_{\mathrm{n}}\right\}(w)$ is either the bottom element of the mereology or else a unique entity. This entity can be a true group object (i.e. a plurality of atomic objects) or an atomic object (i.e. what one would normally consider an individual entity). The underlying function of this object seems to be, that this object (in context) uniquely represents the conjunction of exactly the listed properties. If the sum object is a plurality of atomic objects, importantly, none of the atomic objects in isolation will represent the sum, even though of course they all have the conjoined properties. This underlying rationale leads to the definiteness effects for eigentlich. Before moving on, I want to provide a prose paraphrase for the sum operation in (26). $\sum\left\{\mathrm{P}_{1}, \mathrm{P}_{2} \ldots \mathrm{P}_{\mathrm{n}}\right\}$ can be read as "that unique property concept that, for each possible world, yields the maximal group of entities who have properties $\mathrm{P}_{1}$ and $\mathrm{P}_{2}$ and ... and $\mathrm{P}_{\mathrm{n}}$."

The next step in the analysis of adjectival eigentlich will consist in offering a semantic value for 'eigentlich(e) $N$ ' on the basis of the ingredients that have been introduced so far.

$\llbracket$ eigentlich $N \rrbracket \in \sum\left\{(\operatorname{Nom} \llbracket N \rrbracket), \sum \operatorname{PHÄN}(\llbracket N \rrbracket)\right\}$

Support by discourse context: should entail $\sum(\operatorname{Nom} \llbracket N \rrbracket), \neq \sum$ PHÄN $(\llbracket N \rrbracket)$ for example by naming an $x<\sum(\operatorname{Nom} \llbracket N \rrbracket)$ such that $\neg\left(x<\sum(\operatorname{PHÄN} \llbracket N \rrbracket)\right)$ or by naming

$a=\sum(\operatorname{Nom} \llbracket N \rrbracket), b=\sum(\operatorname{Nom} \llbracket N \rrbracket)$ where $a \neq b$ or by entailments that follow from what the speaker is currently talking about.

In prose, this analysis consists of the following steps:

(i) The noun $N$ has a reliable interpretation, and can be interpreted in a literal sense. (Hence, this analysis does not rest on the idea of 'different ways to understand the word $N^{\prime}$.)

(ii) The literal sense of $N$ is tied to typical properties that could be used to identify $N$ objects (PHÄN $(\llbracket N \rrbracket))$. 
(iii) The literal sense of $N$ is also tied to $\operatorname{Nom}(\llbracket N \rrbracket)$. In practically all cases, $\operatorname{Nom}(\llbracket N \rrbracket)$ is just the singleton set of $\llbracket N \rrbracket$.

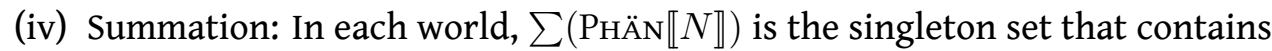
the plurality that exhibits all and exactly the properties in $\operatorname{PHÄN}(\llbracket N \rrbracket)$. If an object $a$ is in the extension of $N$ but not part of this plurality, then $a$ is an object that fails to show some typical property of $N$-hood. If an object is part of the plurality but not an $\mathrm{N}$-object, it could be characterized as a "fake" or "seeming" or "apparent" $N$.

(v) Summation: In each world, $\sum(\mathrm{Nom} \llbracket N \rrbracket)$ is the single plurality of things that are $N$.

(vi) The complex nominal eigentlich(e,er,es) $\mathrm{N}$ can denote either one of the two sums.

If the plurality is not the bottom element, then it is unique and requires definite reference. Let us see some examples.

(28) a. (...) Die EIGENTLICHEN Schüler kommen im Oktober. 'the eig pupils arrive in October'

b. *Ein paar eigentliche Schüler stehen vor der Tür. some eig pupils stand before the door 'there are some eig pupils at the door'

In (28-a), the noun Schüler leads to contrast the plurality of 'nominal' pupils to individuals that could seem to be pupils. Most naturally, the preceding context will have introduced the seeming pupils, i.e. individuals in $\sum$ РнÄN $(\llbracket$ Schüler $\rrbracket)$, whereas the sentence refers to $\sum \mathrm{Nom}(\llbracket$ Schüler $\rrbracket)$, the plurality of pupils in the literal sense. This is a unique plurality, hence the failure in (28-b) to use an indefinite. Note that a partitive construction will be perfectly acceptable: Einige der eigentlichen Schüler stehen vor der Tür 'Some of the eig pupils stand before the door' can be used to refer to a subgroup of the maximality "the true pupils".

Applied to (25)/(26), the analysis allows the NP "die eigentliche Chefin" to refer to the unique individual which shows all typical properties of bosses, and contrast it with the 'nominal' boss. However, it also allows the NP "die eigentliche Chefin" to refer to the unique individual who is the 'nominal' boss, and contrast it with another person who shows typical properties of the boss. Both applications share the entailment that in some sense "the boss is not as she ought to be". This is intuitively a valid prediction.

What does the proposed analysis have to say about the pitch accent on eigentlich? Crucially, the proposed analysis is a choice analysis in that 'eigentlich $(e / r / s) N$ ' refers to one of two possible interpretations $\sum(\operatorname{Nom} \llbracket N \rrbracket), \sum(\operatorname{PHÄN} \llbracket N \rrbracket)$. Given that the 
choice is left to context, eigentlich does not have a constant meaning that could be contrasted with other meanings. In context, however, eigentlich will either be interpreted as the function $f_{\mathrm{NOM}}$ that maps a property $C$ to $\sum \mathrm{NOM}(C)$, or else it will denote the function $f_{P H A ̈ N}$ that maps properties to $\sum$ PнÄN $(C)$. In either case, we can assume that $\llbracket$ eigentlich $\rrbracket_{\mathrm{F}} \rrbracket^{\mathrm{f}}=\left\{\lambda C \cdot \sum \operatorname{Nom}(C), \lambda C\right.$. $\left.\sum \mathrm{PHÄN}_{\mathrm{N}}(C)\right\}$. That is, the contrast between two different ways of determining the extension of $C$ is the constant element in the meaning of eigentlich. This view would warrant the pitch accent on eigentlich as a contrastive focus accent. However, some refinements seem to be needed.

While the above analysis accounts for the pitch accented examples in a natural way, it does not account for the non-accented use of the adjectival eigentlich This is not only so in negated examples but also in examples like (8). I therefore think that the accented cases in fact come about by an interaction of conspiring factors. The use of eigentlich typically takes place in discourse when the notion $N$ is under debate and hence discourse-given. Under such circumstances, speakers evoke a contrast between eigentliche $N$ and other kinds of $N$, as captured in the semantic analysis. Contrastive focus, hence, lies on the entire NP but in view of the fact that $N$ is discourse-given, the AvoidF principle relegates the accent on the adjective (Schwarzschild 1999). This leads to the impression that the adjective carries a focus accent but in fact, it is the full NP that is in contrastive focus. This analysis works better for examples where no NP referents are contrasted:

a. Hans hatte einige Zuhörer, aber eigentliche FANS waren nicht Hans had some listeners, but eig fans were not da.

there.

'John had some listeners but there weren't any true fans present'

b. Der eigentliche charme der Sache ist, daß ...

'The eig appeal of the matter is that ...'

An example like (29-b) in the given intonation could be uttered as a final argument in favor of "the matter" without other charming aspects having been explicitly mentioned before. After all, the use of charm for non-human referents is already non-literal. However, the utterance cleverly evokes the impression that other seemingly charming aspects are at the back of the speaker's mind, and that the positive aspect to be mentioned now just adds the true positive aspect of the matter as a kind of climax. Hence, the utterance in (29-b) effectively conveys that the matter has a lot of positive properties without actually listing them (as revealed by the accent pattern). In conclusion, the analysis offers a good basis for the prosodic behavior of adjectival eigentlich NPs. I will leave the details to be filled in, and return to semantic matters. 
The proposed analysis is open for a wide variety of instantiations of $\mathrm{PHÄN}(\llbracket N \rrbracket)$ and $\operatorname{Nom}(\llbracket N \rrbracket)$. At first sight, this appears a disadvantage because the analysis is not very specific. However, in view of the wide variety of possible uses in real discourse, this flexibility might be an advantage. Consider a case like (30), discussed in Port (2006):

Der EIGENTLICHE Garten ist hinter dem Haus.

'the eig garden is behind the house'

Port argues that (30) can be uttered in view of a small patch of lawn in front of the house. While such patches could already count as 'garden', sentence (30) signals that the speaker will use the word 'garden' in a stricter sense. In this example, it is hard to determine the status of different notions of garden that are at stake. One could assume that eigentlicher Garten ('true garden') is used in the sense "garden with all relevant properties" and contrasted with what 'nominally' could be classed as garden. In this analysis, the nominal extension of Garten can comprise little patches of green as well as more extended gardens, and the eig garden is a restricted form of 'all gardens'. Alternatively, however, the speaker could be intending to say "in a certain phenomenological sense, this little patch could fulfill the criteria to be a garden - a fenced piece of lawn in front of a house. Yet, the nominal sense of Garten includes a functional element and refers only to that piece of lawn that is functionally assigned to the house as being its garden. This sense of Garten does not apply here". However, both analyses have in common that the speaker points out that we could use Garten in two senses, and demonstrates the difference on the basis of discourse referents. This is exactly the intuition underlying examples like (30). Moreover, the analysis predicts that the speaker believes that the word Garten does have a literal sense, and that sentences like (30) are not used to point out a language error. Again, this is a valid prediction. The extra level of complexity that remains in example (30) is the fact that Garten, unlike pupil or boss, does not have a fixed legal or institutional definition.

To conclude the discussion of adjectival eigentlich, the analysis predicts that it does not make much sense to negate eigentlich. The only reasonable denotation for un-eigentliches $N$ could be the opposed semantic value in $\left\{\sum(\operatorname{Nom} \llbracket N \rrbracket)\right.$, $\left.\sum\left(\mathrm{PHÄN}_{4} \rrbracket \rrbracket\right)\right\}$. Given that eigentlich has the choice to pick up either of the two, uneigentlich simply provides a morphologically more complex way to express the same thing. Likewise, it does not make much sense to use un-eigentlich to name the "second meaning" after the first one has been chosen. If used in this way, 'un-' would not have a constant interpretation but serve to express something like the other operator. This is not an acceptable form of negating a concept (see e.g. Horn 2002). Only in those rare cases where the adjective is used context-independently to map a property $\mathrm{N}$ to a sub-property can un- apply. In this case, the prefixed adjective constantly refers to the complementing sub-property. Examples comprise 
cases like eigentliches/uneigentliches Integral, and a few more as mentioned above.

\section{[4] ADVERBIAL USE}

While most other studies on eigentlich address only its adverbial use, the present study deliberately spent time on a close investigation of the adjectival case. This effort will pay off in the present section. I will argue that the adjectival use can be adapted to the adverbial case with minor changes. At the end of the section, I will briefly point out why other possible analyses, not inspired by the adjectival case, do less justice to the data.

\section{[4.1] Stress = contrastive topic accent}

The first important observation concerns the prosodic facts of the adverbial use. It was mentioned in section 2 that adverbial eigentlich can occur stressed or unstressed, and that authors tend to correlate this difference with two possible uses (which will be confirmed in the present analysis). It has, to my knowledge, never been pointed out that the stress of stressed eigentlich (as in (31)) can not be a simple focus accent. In fact, (31) with a single accent on eigentlich is prosodically and pragmatically ill formed (see (32)). The hearer perceives but cannot interpret the single accent. A more appropriate prosody is given in (33) where a second accent occurs on keine ('no'); on the interpretation of accent contours see Büring (2007) and references therein.

(31) Eigentlich habe ich keine Zeit.

eig have I no time (no accent pattern)

(32) single $\mathrm{HL}^{*}$ accent is illformed:

*Eigentlich habe ich keine Zeit.

(33) contrastive topic $\mathrm{L}^{*} \mathrm{H}$ accent is acceptable:

EIGENTLICH/ habe ich KEINE $\backslash$ Zeit.

This suggests that adverbial eigentlich can associate with a second focus, and that an analysis in terms of contrastive topic would be more faithful to the data than one in terms of simple focus. I will completely disregard the option of an uninterpreted "lexical" accent here. Let us investigate how different loci of the second accent influence our understanding of the overall message conveyed.

\section{[4.2] eigentlich in association with focus}

Sentences like (33), as well as (34) below, strongly suggest certain kinds of context of use. They echo situations that we all know too well, and we would strongly tend to read them in the prosodic pattern that seems most natural in these situations. Hence, the literature contains no discussion of the fact that other accents would be possible in other situations. 
(34) Eigentlich heiße ich Thомаs. eig am-named I Thomas

Let us take the minimal pair in (35)/(36) as starting point to investigate accentuation.

$$
\begin{aligned}
& \text { Eigentlich } \text { DUSCHEF }_{\mathrm{F}} \text { ich gerade. } \\
& \text { eig take-a-shower I now }
\end{aligned}
$$

Eigentlich dusche $\mathrm{ICH}_{\mathrm{F}}$ gerade.
eig take-a-shower I now

Both sentences have a ring of protest to them and suggest possible continuations which spell out this undertone. However, different continuations are natural for either example.

(35') Eigentlich DUSCHE $_{\mathrm{F}}$ ich gerade... but there are certain suggestions $p$ around that seem to be based on the assumption that I am not taking a shower. E.g. $p=$ You ask me to answer the phone.

(36') Eigentlich dusche $\mathrm{ICH}_{\mathrm{F}}$ gerade... but there are certain propositions $p$ that are more coherent with someone else taking a shower. E.g. $p=$ Tom occupies the shower.

The observations in (35) and (36) are hard coherency facts. Violations are as bad as coherency violations can ever be. A cross-change of the continuations as in (35) and (36) yields clearly incoherent discourses.

(35") \# Eigentlich DusCHE $\mathrm{F}_{\mathrm{F}}$ ich gerade. And/but Tom occupies the shower.

(36") \# Eigentlich dusche $\mathrm{ICH}_{\mathrm{F}}$ gerade. And/but you ask me to answer the phone.

An adequate analysis of the meaning of eigentlich needs to be able to predict these differences in coherency, and hence has to take focus into account. Note that the default inference blocking analysis by Schmitz and Schröder (2004) correctly predicts that the acceptable cases are acceptable (default inferences of $S$ are contradicted by next sentence). Yet, it cannot explain why the nature of possible contrasting propositions is influenced by focus structure.

\section{[4.3] Adverbial eigentlich: What holds and does not hold true in $w_{0}$ ?}

I will propose an analysis for adverbial eigentlich that raises the meaning of the adjective to the propositional level. Adverbial eigentlich takes the proposition $p$ expressed by the sentence as its argument. Once again, it refers to two propositions that can be derived from $p$ :

- $\operatorname{Nom}(p)=$ those worlds where $p$ (the proposition expressed by the sentence) 
holds true

- $\operatorname{PHÄN}(p)=$ conjunction of propositions $\left\{Q_{1}, Q_{2} \ldots Q_{n}\right\}$ which are normally indicative for $p$-worlds.

The definitions are slightly simpler than those in section 3, refraining from sum formation. This is due to the fact that adverbial eigentlich shows no definiteness effects. The semantic contribution of eigentlich is to state that the two sets of worlds $\operatorname{Nom}(p)$ and $\operatorname{PHÄN}(p)$ differ. This difference is evidenced by the real world $w_{o}$ which is an element of one, but not the other set.

Eigentlich heiße ich Thomas. Aber jeder nennt mich Ede.
eig named-am I Thomas. But everybody calls me Ede.
'My name is Thomas really. But everybody calls me Ede'

The first sentence in the discourse in (37) makes two statements, actually. First it states that $w_{0}$ is in the proposition $p=$ 'my name is Thomas'. Second, it states that $w_{0}$ is not in the proposition $\operatorname{PHÄN}(p)$. Hence we know that at least one of the typical indicative circumstances that normally come along with 'my name is Thomas' does not hold true in $w_{0}$. Typically, a following aber ('but') sentence will make it clearer which of the $Q_{i}$ is false in $w_{0}$. In the present example, $Q_{i}=$ 'everyone calls me Thomas' as a typical side effect of a person's name being Thomas. The content of the 'but' sentence entails the negation of $Q_{i}$. We have hence effectively recast the analysis of Schmitz and Schröder (2004) in a truth conditional setting.

Note that eigentlich denies the truth of evidence for $p$, not default inferences simpliciter. This is made clear by the following incoherent discourse:

$$
\begin{aligned}
& \text { Eigentlich ist Dani kahlköpfig. \#Aber Dani ist eine Frau. } \\
& \text { eig is Dani bald. But Dani is a female. } \\
& \text { '('In fact, Dani is bald. But Dani is a woman.)' }
\end{aligned}
$$

It is certainly true that bald persons are typically male persons. Hence, the second sentence contradicts a default inference of the first sentence, and can serve to block default inferences (Schmitz and Schröder do not specify a particular framework of default logic; the model theoretic reconstruction of non-monotonic reasoning in Eckardt (1999) reveals some of the assumptions about normality and defaults). The example in (38) should be well-formed, yet this prediction is not borne out. In terms of the truth conditional analysis presented here, we can state that baldness is not one of the phenomenological features that are used to identify male persons. The eigentlich in the first sentence tells us that one in a set of characterizing or defining propositions $Q_{i}$ does not hold true. The second but clause is supposed to spell out which one. And 'Dani is female' is just not suited to do this, because 'Dani is male' is not a good phenomenological clue to single out persons 
who have no hair.

I want to end this subsection by pointing out a possible variant of the analysis. In principle, the analysis would allow the same choice of uses of eigentlich for propositions like the adjectival case.

$$
\begin{aligned}
& w_{o} \in \operatorname{Nom}(p) \text { and } w_{o} \notin \operatorname{PHÄN}(p) \\
& w_{o} \in \operatorname{PHÄN}(p) \text { and } w_{0} \notin \operatorname{Nom}(p)
\end{aligned}
$$

I am not sure, however, how prominent the second option is in actual practice. Attempts to create examples of this kind sound somewhat artificial and forced, which is not the case for the adverbial. I will therefore leave it open for the moment whether this second use really exists, and will confine myself to sideremarks when such a second option might occasionally do better justice to the data.

\section{[4.4] The pragmatics of prosody}

In section 4.2 it was argued that the prosody of the sentence can serve to further narrow down the expectations as to what kinds of typical circumstance $Q_{i}$ might be violated. Moreover, we observe that uses of eigentlich often come along with a L*H accent that is typically used, in German, to indicate contrastive topics. In this section I will show that these prosodic patterns are indeed meaningful and receive their normal pragmatic interpretation. My analysis will rest on Büring (2003) where an analysis of complex pitch accent patterns in terms of contrastive topic and focus is proposed. We will use the German variant of this analysis, which differs from the English version in that the contrastive topic accent is a $\mathrm{L}^{*} \mathrm{H}(\mathrm{sim}-$ pler than the English counterpart) and always has to precede the focused constituent. The analysis reveals that contrastive topicalization presents an utterance as part of a strategy where a topical question is answered by addressing several sub-questions in turn. Hence, an utterance like die WEIBlichen $\left(L^{*} H\right)$ Popstars trugen Kaftans $\left(\mathrm{HL}^{*}\right)$ ('the female pop stars wore caftans') answers the sub-question 'What did the female pop stars wear?' and relates to the contrasting sub-question 'What did the male pop stars wear?' Both utterances together serve to settle the discourse topic 'What did the pop stars wear?'. The information structure of the utterance is as follows: Die weiblichen ${ }_{C T}$ Popstars trugen Kaftans $s_{F}$ where CT and F both receive a systematic semantic/pragmatic interpretation. I will use the interpretations proposed in Büring (2003); the reader is referred to the article for details.

The most important step consists in understanding the semantic components of a sentence with adverbial eigentlich, a CT accent on eigentlich and a focus accent elsewhere in the clause. It will turn out that the CT construction creates a clearly defined logical tie between the eigentlich-clause and the following sentence, usually referred to as the "contrasting sentence", and also the sentence which, in 
terms of Schmitz and Schröder (2004), offers indications as to which default inferences are blocked.

According to the general pragmatics of $\mathrm{CT}+\mathrm{F}$ constructions, we should expect that (i) the meaning of eigentlich is contrasted with a focus alternative ALt('eigentlich'), that (ii) the sentence addresses a local question under discussion about eigentlich(S), and (iii) the sentence is part of a strategy that will next address a contrasting question under discussion about Alt('eigentlich') (S'). The first important player that we need to find is ALT('eigentlich'). This player is difficult to paraphrase because, like in the adjectival case, there is no good lexicalization of the focus alternative of eigentlich. Jocular "un-eigentlich" in quotation marks is the best approximation that one can find in actual conversational situations. ${ }^{4}$ However, in terms of the semantic analysis of eigentlich above, the semantic contribution of the focus alternative can be stated quite clearly:

$$
\begin{aligned}
& \llbracket \text { eigentlich } \rrbracket=\lambda p \lambda w .(\operatorname{Nom}(p)(w) \wedge \neg \operatorname{PHÄN}(p)(w)) \\
& \operatorname{ALT}(\llbracket \text { eigentlich } \rrbracket)=\lambda q \lambda w .(\neg \operatorname{Nom}(q)(w) \wedge \operatorname{PHÄN}(q)(w))
\end{aligned}
$$

In a loose prose paraphrase, eigentlich serves to state that, for some given proposition $p$, the current world is such that $p$ nominally holds true, and the current world does not look as if $p$ were true. The alternative to eigentlich states that for some proposition $q$, the current world does not make $q$ true even though it might look as if $q$ were true. In the contrastive topic construction, the proposition $p$ will be the propositional content of the eigentlich sentence. The contrastive proposition should be one that differs from $p$ in exactly that second position that is indicated by focus. What is non-standard about the contrastive topic construction is that the second part of the strategy can never fully exhibit the appropriate $\mathrm{CT}+\mathrm{F}$ structure, due to the fact that there is no good word that expresses ALT( (eigentlich $\rrbracket)$. In order to show how contrast, focus and discourse conspire, I will discuss an example in detail.

(39) EigentLich $\mathrm{CT}_{\mathrm{CT}}$ heisse ich Tom $_{\mathrm{F}}$.

a. $\quad \llbracket S \rrbracket^{\mathrm{o}}=\lambda w \cdot\left(\operatorname{Nom}\left(\lambda w^{\prime} \cdot \operatorname{NAmED}\left(\mathrm{Me}\right.\right.\right.$, TOM, $\left.\left.w^{\prime}\right)\right)(w)$

$$
\left.\wedge \neg \operatorname{PhäN}\left(\lambda w^{\prime} \cdot \operatorname{Named}\left(\text { Me, Tom, } w^{\prime}\right)\right)(w)\right)
$$

Ordinary meaning of the sentence: 'We are in a world $w$ in which my name is Tom, but $w$ fails to show one of the typical features of worlds in which my name is Tom'

[4] For instance, you may overhear conversations like the following.

(i) a. Eigentlich bin ich schon satt

'I am eig no longer hungry.'

b. Na, und "un-eigentlich“? Was möchtest Du noch essen?

'Well, and un-eig? Which dish can I offer you?' 
b. $\quad \llbracket S \rrbracket^{\mathrm{f}}=\left\{\lambda w \cdot\left(\operatorname{Nom}\left(\lambda w^{\prime} \cdot \operatorname{NAMED}\left(\mathrm{Me}, \operatorname{Tom}, w^{\prime}\right)\right)(w) \wedge\right.\right.$

$\neg \operatorname{PhÄN}\left(\lambda w^{\prime}\right.$.NAmED $\left(\right.$ Me,Tom, $\left.\left.\left.w^{\prime}\right)\right)(w)\right)$

$\lambda w \cdot\left(\operatorname{Nom}\left(\lambda w^{\prime} \cdot \operatorname{NamED}\left(\operatorname{Me}, \operatorname{EDE}, w^{\prime}\right)\right)(w) \wedge\right.$

$\left.\left.\neg \operatorname{PHÄN}\left(\lambda w^{\prime} \cdot \operatorname{NamED}\left(\operatorname{Me}, \mathrm{EDE}, w^{\prime}\right)\right)(w)\right), \ldots\right\}$

$=\llbracket{ }^{'}$ what is my name, eigentlich?' $\rrbracket^{\mathrm{o}}$

Focus semantic value of the sentence: Set of propositions of the form "eig, my name is X". Semantically identical to the question "what is my name, eig?'.

c. $\llbracket S \rrbracket^{\text {ct }}$

$=\{$ 'what is my name, eigentlich?', 'what is my name, ALT-eigentlich?'\}

$=\left\{\left\{\lambda w .\left(\operatorname{Nom}\left({ }^{(} m y\right.\right.\right.\right.$ name is $\left.T^{\prime}\right)(w) \wedge \neg$ PHÄN $\left({ }^{\prime}\right.$ my name is $\left.\left.T^{\prime}\right)(w)\right)$, $\lambda w$. $\left(\right.$ Nom('my name is $\left.E^{\prime}\right)(w) \wedge \neg$ РнÄN('my name is $\left.\left.\left.E^{\prime}\right)(w)\right), \ldots\right\}$

$\lambda w .\left(\neg \operatorname{Nom}\left({ }^{\prime} m y\right.\right.$ name is $\left.T^{\prime}\right)(w) \wedge$ PнÄN $\left.\left({ }^{(' m y ~ n a m e ~ i s ~} T^{\prime}\right)(w)\right)$, $\lambda w .\left(\neg \operatorname{Nom}\left({ }^{\prime}\right.\right.$ my name is $\left.E^{\prime}\right)(w) \wedge \operatorname{PHÄN}\left({ }^{\prime} m y\right.$ name is $\left.\left.\left.\left.E^{\prime}\right)(w)\right), \ldots\right\}\right\}$

d. Propositions in $\llbracket S \rrbracket^{\text {ct }}$ in English paraphrase:

$\{$ ' 'my name is T, but matters don't look that way', 'my name is E, but matters don't look that way', ... \}, \{'It looks as if my name were T, but that's not true', 'It looks as if my name were E, but that's not true', ...\} \}

The step-by-step computation of ordinary semantic value of $S$, focus semantic value of $S$ and contrastive-topic value of $S$ reveals that the single components of the sentence contribute in a fully systematic fashion to reveal the pragmatic skeleton of eigentlich discourse. The paraphrases in d. show that the indicated strategy matches the observed structure of eigentlich-sentences in discourse. A first utterance, containing 'eigentlich', serves to state what truly is even though matters do not look that way. In a second utterance the speaker can go on and point out what our world looks like, even though the respective proposition is false in our world. Let us see how a typical continuation will fit into this strategy. ${ }^{5}$

(40) S1: EIGENTLICH $\mathrm{CT}_{\mathrm{C}}$ heisse ich Tom $\mathrm{F}_{\mathrm{F}}$

S2: Aber jeder nennt mich Ede.

The second sentence is supposed to contribute to the following implicit question:

(41) 'For which alternative name $\mathrm{X}$ does the world look as if my name were $\mathrm{X}$, yet it is not actually so?'.

[5] Admittedly, the eigentliche eigentliche name of the person called 'Ede' is Thomas. Due to its length, however, this eigentliche eigentliche name would have caused awkward line breaks in formulae. 
The second sentence contributes a proposition that would typically lead us to expect that 'speaker's name is Ede' is true. That is, we are in a world which phenomenologically looks like a 'my name is Ede' world. However, our world is not a 'my name is Ede' world in the technical sense (NOM), because sentence 1 of the discourse has just asserted that the name of the speaker in the technical sense is 'Tom'. Against the knowledge background supplied by sentence 1, hence, sentence 2 offers a full answer to the remaining implicit question of the strategy. The second sentence does even more in that it names a specific proposition that would be typical for a 'my name is Ede' world. A literal answer to the remaining implicit question could confine itself to 'it might look as if my name were Ede' without any information as to what precisely creates the impression that the speaker's name might be Ede. ${ }^{6}$

Let us proceed to one of the examples that have been described as "weakening of the proposition". In the following two-sentence discourse, the speaker weighs reasons to reject or accept a proposal.

(42) (A: Do you want to join me to the movies tonight?)

B: S1 Eigentlich muss ich arbeiten. S2 Aber ich komme trotzdem mit.

'Eig I have to work. But I will join you nevertheless.'

I assume that $\mathrm{S} 1$ has the following information structure:

\section{EIGENTLICH $_{\mathrm{CT}}[\text { muss ich arbeiten }]_{\mathrm{f}}$}

The full sentence content is in focus, and the underlying strategy should consist of the following two questions, which I have numbered for ease of reference.

[EIGENTLICH ${ }_{\mathrm{CT}}[\text { muss ich arbeiten }]_{\mathrm{f}} \rrbracket^{\text {ct }}$

$=\{\mathrm{Q} 1$ : 'what is the world eigentlich like, in spite of contradicting evidence?', Q2: 'what does the world look like, even though it is not true?' \}

I will refrain from offering the full representation in a formal format. However, note that sentence-wide focus allows the speaker to address a maximally varied set of alternative propositions $q$ as focus alternatives. S1 answers Q1 in the strategy: The world is such that the speaker has to work. Such obligations are typically evidenced by the speaker's being busy, the speaker not leaving her desk for days, the speaker just taking breaks to have a cup of tea, etc. However, the eigentlich statement already asserts that one of these typical pieces of evidence for 'speaker has to work' fails to hold. Not surprisingly, sentence S2 reveals which one. Once again, S2 contributes to question Q2 in an indirect manner. It names a typical

[6] In this sense, a fully matching answer like 'uneigentlich heisse ich Ede' ('un-eig, my name is Ede') is underinformative. If you consider the 'jocular literal answer', it is easy to see that indirect answers are better answers in this case. 
feature of worlds where the speaker does not have to work: 'I agree to go to the movies tonight'. The current world phenomenologically shares this feature of 'I do not have to work' worlds even though - as asserted in S1 - the proposition 'I do not have to work' is not true. We can indirectly reconstruct the focus alternative of [muss ich arbeiten $]_{\mathrm{f}}$ ('I have to work'):

$$
\llbracket[\text { muss ich arbeiten }]_{\mathrm{f}} \rrbracket^{\mathrm{f}}=\{\text { 'I have to work', 'I don't have to work' }\}
$$

Under this analysis, the short discourse in (42) once again exhibits a fully coherent example of a strategy. It also becomes clear why the eigentlich sentence alone is not sufficient for the addressee as an agreement to the proposal. Sentence (43) in the indicated information structure only announces that something in the present world is not as it should be in an 'I have to work' world. It does not commit the speaker to anything - specifically as the announced counterevidence is subject to the speaker's decisions. This turns eigentlich sentences into ideal discourse moves, allowing the speaker some time to think while leaving all options open.

Let me summarize the building blocks of the present analysis of adverbial eigentlich in cases discussed so far.

- eigentlich relates the proposition $p$ expressed by the sentence to two sets of worlds $\operatorname{Nom}(p)$ and $\mathrm{PHÄN}(p)$.

- The overall sentence denotes those sets of worlds $w$ that are in Nom(p) but not in PHÄN(p). Hence, the function expressed by eigentlich can be stated as follows:

$\llbracket$ eigentlich $\rrbracket=\lambda p \lambda w .(\operatorname{Nom}(p)(w) \wedge \neg \operatorname{PHÄN}(p)(w))$

- eigentlich can be focused, and will give rise to the focus alternative $\operatorname{ALt}(\llbracket$ eigentlich $\rrbracket)=\lambda q \lambda w .(\operatorname{PнÄN}(q)(w) \wedge \neg \operatorname{Nom}(q)(w))$

- eigentlich can be in contrastive focus. In this case, it "associates" with a second focus in the sentence in the way all contrastive foci do. The second focus can be on a lower constituent, or on the entire sentence except eigentlich.

- Contrastive topic on eigentlich offers the typical starting point for an 'eigentlich S1. But S2.' discourse. The discourse follows a strategy with two underlying questions. S1 answers the question what the world really is like. S2 answers the question what the world looks like, by contributing a proposition which is typically linked with some second state of affairs which contradicts the content of S1. 
The present analysis derives the 'blocking of default inferences' in an indirect manner. All eigentlich - but discourses contrast a state of affairs $p$ against evidence $\phi$ for a conflicting state of affairs $q$. This evidence $\phi$ will contradict some other piece of evidence $\psi$ that is normally typically linked with $p$ worlds. The default inference would hence be the following.

(46) Usually if $p$ then $\psi$.

If the underlying logic of an eigentlich-but discourse in fact consisted in blocking a default inference, one might wonder why the blocked inference is not simply and straightforwardly named. Would it not be most cooperative to say "eigentlich, $p$ is the case, even though $\neg \psi$ "? According to an analysis in terms of blocked default inferences, such uses should be the best and most cooperative way to use eigentlich. In actual fact, however, linguistic descriptions rest on a shared intuition that eigentlich-but data constitute the prototypical core data, whereas eigentlich-even though examples are at best mentioned tangentially in formal analyses. ${ }^{7}$ We will turn to these in the next section, under the heading of "derived uses". The present analysis predicts that the eigentlich-but use addresses the underlying strategy in an optimal manner. Notably, the analysis assumes that the main function of an eigentlich statement is to contrast the world as it is with the world as it looks. Blocked default inferences are a side effect of this pragmatic function, but not its primary aim.

\section{[4.5] Extension to Questions}

Note that this analysis naturally extends to stressed eigentlich in wh-questions. We have, in fact, used these questions in the contrastive topic analyses above.

Wie heißt Du EIgENTLICH?

How are-called you eigentlich?

Eigentlich heisse ich ThOMAs. (But everyone calls me "Ede")

(48) Wann hast Du EIGENTLICH Sprechstunde?

When have you eigentlich conference hour?

Eigentlich habe ich Donnerstags Sprechstunde.

Eigentlich have I on-Thursday conference hour.

(But I offer advice to interested students at any time of the week.)

Focus in questions standardly serves to contrast them with other questions. These alternative questions generally look like the original question, except that the focused constituent is replaced by one of the focus alternatives. In the case of a focus on eigentlich, then, the alternative question will have the same structure as the

[7] Notably, Schmitz and Schröder (2004) build their entire analysis on basis of eigentlich-but examples. 


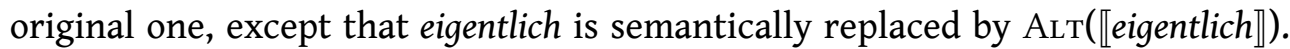
In the present example, this semantic alternative could be expressed as seemingly, apparently. The speaker implicitly evokes a question "When do you seem to have conference hours?", or more precisely, "What time looks as if it could be the time of your conference hour?" The speaker alludes to facts in the context that answer this question, such as for example "It is Monday morning at 8, and I am already supervising students, so you might think that this is my conference hour." Questions like (47) and (48) are standardly used if the answer $q$ to the question about what seems to be the case is salient in the context. The respective propositions are given in brackets above. The contribution of the question in (47) could be paraphrased as follows:

(47') Contextually salient: 'What name $x$ is such that a contextually given fact $q$ suggests that $x$ is your name?'

Given fact q: everyone calls you 'Ede'.

Suggested answer: 'Ede' is the name such that ... Ede might be your name. Explicit question: What name is eigentlich your name?

Explicit answer: Eigentlich, my name is 'Thomas'

Use of eigentlich licensed by alternative q: 'Your name is Ede'.

The semantics and pragmatics of the answer is exactly the same as the one that was computed in the previous section. I refrain from a second spell-out here. Note that an analysis which cuts orthogonally through standard semantic analyses (Schmitz and Schröder 2004 would certainly count as one amongst these) is problematic at this point. Specifically, an analysis in terms of blocked default inferences will make the claim that the eigentlich question asks for a fact that the speaker does not yet know, but she already is supposed to know which default entailment of this unknown fact she wants to cancel. While this might be a technically feasible claim, it does not plausibly model actual question-answer discourse.

\section{[5] DERIVED PARTICLE USES}

In this section, I want to outline usages of eigentlich which deviate more and more from the analysis in section 4 . The analysis in 4 is tailored for cases where eigentlich associates with focus, brings alternative propositions to the fore, refers to a contrasting proposition $q$ in context and conveys that $q$ would lead one to expect one of these (false) alternatives rather than the actual facts. Deviant cases vary from those that differ only slightly from those discussed in the previous section to those where eigentlich arguably does not contribute in the sense of section 4 .

The first constellation is still closely related to the systematic use that has been analyzed in section 4 , and in fact has been mentioned briefly at the end of the previous section: Continuations with obwohl ('even though') instead of aber 
('but').

Ich mag Peter eigentlich, obwohl er manchmal frech wird. I like Peter eig although he sometimes nasty becomes 'As a matter of fact, I like Peter although he's sometimes nasty.'

Schematically, the rationale behind (49) is this.

S, obwohl P.

P normally would lead you to expect not S. Here, however, S holds true.

This type of use is fully in line with a 'blocked inference' analysis. Note that (49) with a pitch accent on eigentlich is deviant. A literal analysis like in section 4 will look as follows.

$$
\begin{aligned}
& \llbracket \text { eigentlich [ Ich mag Peter }] \rrbracket^{\mathrm{o}} \\
& =\lambda w .\left(\operatorname { N o m } \left({ }^{\prime} I \text { like Peter') }(w) \wedge \neg \operatorname{PHÄN}\left({ }^{\prime} \text { I like Peter') }(w)\right)\right.\right.
\end{aligned}
$$

According to this analysis, sentence (49) should state that in a technical sense I like Peter, although it might look as if I didn't. Intuitively, this is not at all the message that is conveyed by the discourse in (49).(49) states that the speaker likes Peter, and is prepared to act according to this sympathy (so the world, in all respects, will also look like a world where the speaker likes Peter), and that she is moreover aware of the fact that Peter shows certain types of behavior that would normally lead people to not like him. In terms of its paraphrase, then, the content of (49) does not match earlier paraphrases that were used to spell out the contrast between what the world is and what the world looks like.

It is extremely hard to pinpoint the origins of the global difference between eigentlich-but examples and eigentlich - although examples. One major difference between eigentlich - but examples and eigentlich - although examples, intuitively, consists in the role that various conflicting propositions will play in further discourse. In an eigentlich - S1 - but S2 construction, the speaker signals that S2 is more salient and will be considered a leading fact in the sequel. In an eigentlich $S 1$ - although S2 example, the speaker is willing to continue the discourse with a focus on S1 which is the most salient fact, in spite of S2. This can be illustrated with the following minimal pair.

(52) Eigentlich ist dein Zimmer schön aufgeräumt, obwohl im Eck noch etwas Krempel liegt.

eig is your room nicely cleaned, even though in the corner still some rubbish lies

'Your room is eig nice and clean, even though it is still a little messy in one corner.' 
The speaker is willing to acknowledge the room as being in the state of "cleanliness", disregarding minor faults. This is definitely not so in (53).

$$
\begin{aligned}
& \text { Eigentlich ist Dein Zimmer schön aufgeräumt. Aber im Eck liegt } \\
& \text { eig is your room nicely cleaned. But in-the corner lies } \\
& \text { noch etwas Krempel. } \\
& \text { still some rubbish } \\
& \text { 'Your room is nicely cleaned, but it is still a little messy in one corner' }
\end{aligned}
$$

In this case, the speaker most likely will insist that the mess in the corner has to be removed before the state of "cleanliness" is fully acknowledged. ${ }^{8}$

In many cases, the differences between eigentlich - but and eigentlich - although variants are subtle. However, the eigentlich - although use opens up a road that is definitely blocked for eigentlich - but uses. Pushing the although use even further, the speaker can use eigentlich without any obligation to specify any additional proposition which would contradict $S$, or lead one to expect Not $S$. I will call this the "pensive use of eigentlich" and show examples presently. Uses of this kind do not suggest blocking of default inferences, or phenomenologically conflicting propositions. The utterances in (54) - (56) show some cases, and the English translations are faithful in that they at best convey a moment of reflection before making the assertion. Formally, the examples require a de-accented use of eigentlich.

(54) Peter ist eigentlich ein netter Kerl.

'Thinking about it, Peter is actually a nice guy.'

(55) Wir schlafen eigentlich nur.

'Thinking about it, we are sleeping all the time.'

Da hast Du eigentlich recht.

'Thinking about it, you are right.'

In using sentence (54), the speaker asserts that 'Peter is a nice guy', that she has come to this conclusion after some thinking about Peter's character, and that there is currently nothing that would cast doubt on this fact. Using (56), the speaker signals friendly agreement, after a moment's reflection or doubt. (The doubts will never have been uttered explicitly: Sentence (56) would never serve to end a longer monologue where the speaker lists the pros and cons to a position uttered by the second interlocutor.) And so on.

If we were to speculate on the development of the "pensive use of eigentlich"

[8] Examples like this could suggest that adverbial eigentlich, like its adjectival counterpart, could require a choice analysis. In the present case, it is doubtful whether we want to license the inference from eigentlich, the room is clean to 'the room is clean' holds true in the nominal sense of the sentence. If needed, the analysis of section 3 can easily be extended to adverbial eigentlich. I will not burden the discussion with this extra move. 
from the conceptually richer adverb uses, a metalinguistic intermediate stage could be hypothesized. The speaker would make an although statement, signaling that the content of the sentence will serve as the basis for further discussion: let's act accordingly. The content of the although phrase could be about the speaker trying to think about counterarguments to $S$.

(57) Wir schlafen eigentlich nur.

Eigentlich: we sleep all the time. Even though: I tried hard to think of other interesting things that I could tell you we're doing.

(58) Da hast Du eigentlich recht.

Eigentlich: you are right. Even though: I tried hard to think of counterarguments to your position.

At present, I am unable to offer a decent analysis of such a - speculative - intermediate use in terms of metalinguistic eigentlich in any serious sense. It seems clear to me that the literal sense of eigentlich in terms of the preceding sections will not be straightforwardly applicable, even if we raise it to the level of speech acts. The mental and semantic processes that lead from a straightforward $\mathrm{CF}+\mathrm{F}$ structure via a related eigentlich-although sequence to an undertone like the one paraphrased in (57) are still beyond formal analysis. Curiously, the pensive undertone carries over to unstressed eigentlich in questions. These suggest that the question came to mind after some thinking/interaction. This interaction can be friendly ('casual question') or aggressive.

(59) Sind Sie eigentlich wahnsinnig?

(Having interacted with you for some time I feel pressed to ask:) 'Are you mad?'

(60) Wie heissen Sie eigentlich? ${ }^{9}$

(Having talked to you for some time, I realize that I could ask:)

'What's your name?'

(61) Wollen Sie eigentlich noch Kuchen?

(Let me interrupt our friendly ongoing interaction to ask you:)

'Would you like some more cake?'

The unstressed eigentlich in questions is definitely bad if the speaker starts an interaction with the hearer with the intention of asking exactly this question, or if the question is an essential part of a professional interaction between speaker and hearer. The following exchanges are all marked, the effects ranging from "funny"

[9] Also warranted in an aggressive interaction like in the preceding example. 
to "rude/offensive"10.

(62) Waiter when approaching customers:

Was wollen Sie (\#eigentlich) essen?

what want you eig eat

$\approx$ 'What do you want to eat anyway?'

(63) Dentist asks whimpering patient:

Haben Sie (\#eigentlich) Schmerzen?

have you eig pains

$\approx$ 'By the way, are you in pain?'

(64) Police officer checking you after you passed a red traffic light:

Wie ist (\#eigentlich) Ihr Name?

what is eig your name?

'What's your name anyway?'

\section{[5.1] Postlude: A dialectal twist}

When my colleague and I tried to verify our intuitions about possible and impossible uses of adjectival eigentlich via GOOGLE, we were surprised by accidental matches for patterns that the analysis, as well as our intuitions, would not support. Among these were hits for ein eigentlicher/-s in positive contexts, quantified uses like die meisten eigentlichen ... and uneigentliche in non-expert language. Closer investigation revealed that all such matches came from Swiss sites, or were quotes from Swiss authors or newspapers, or were on sites / by authors with a very likely Swiss background (e.g. Swiss embassy in Berlin). Further explorations on such sites suggest that Swiss German uses eigentlich more or less as a synonym of wirklich, echt ('true'). Specifically, Swiss eigentlich needs no contextual licensing, can hence be used in quantificational NPs, and has a well-defined antonym. We could not so far establish the prosodic patterns of adjectival eigentlich in Swiss German but would expect that accenting is much freer than in German. In summary, Swiss eigentlich offers a minimally contrasting 'normal' eigentlich variant and hence highlights the context dependency and discourse function of German eigentlich.

\section{[6] SUMMARY}

In the present paper, I proposed a truth conditional analysis of adjectival and adverbial eigentlich. I assume that the item serves to relate a property or proposition $C$ to two derived cognitive objects: $\operatorname{Nom}(C)$, the nominal sense of $C$ and $\mathrm{PHÄN}_{\mathrm{N}}(C)$, the conjunction of properties (propositions) that together would offer

[10] Hence, learners of German need to be cautioned against the idea that eigentlich invariably makes a question sound more polite! 
phenomenological evidence for a case of $C$-hood. These two derived concepts underlie the use of both, adjectival and adverbial eigentlich, but the two cases differ in the details. Adjectival eigentlich shows definiteness effects, which arise due to the fact that the phrase eigentlich $(e / r / s) N$ refers to the unique plural object that exemplifies the sum of properties in $\operatorname{Nom}(C)$ or $\operatorname{PHÄN}(C)$ respectively. Eigentliche/r/s $\mathrm{N}$ is typically used in situations where the discourse content entails that the two concepts are different. However, statements about empty domains (es gibt hier keinen eigentlichen Chef = 'there is no true boss here') or other uses without explicit contrast are possible, and in the range of the proposed analysis. Finally, the adverbial use is characterized by the fact that eigentlich has a choice semantics: The full phrase eigentliche/r/s $N$ can refer either to $\operatorname{Nom}(\llbracket N \rrbracket)$ or PнÄN $(\llbracket C \rrbracket)$, depending on the speaker's intentions. This also explains why eigentlich can hardly be negated.

Adverbial eigentlich is mereologically simpler. It maps propositions to propositions and does not create pluralities of worlds. Likewise, a majority of cases can be analyzed on basis of the assumption that eigentlich $\mathrm{S}$ states that the world is in $\operatorname{Nom}(\llbracket S \rrbracket)$, but not in $\operatorname{PHÄN}(\llbracket S \rrbracket): \llbracket$ eigentlich $\rrbracket=\lambda p \lambda w .(\operatorname{Nom}(p)(w) \wedge \neg \operatorname{PHÄN}(p)(w))$. eigentlich has a systematically available focus alternative, and can be used in focus constructions and contrastive topic constructions in both assertions and questions. I demonstrated that the predicted semantic representations are faithful to the intuitive meanings of examples in many cases; and specifically in those cases where prosody indicates a clear information structure.

The proposed analysis ties in nicely with an earlier formal analysis proposed by Schmitz and Schröder (2004), treating eigentlich as a blocker of default inferences. The present proposal goes beyond its predecessor in several respects. First, it offers a uniform analysis for adjectival and adverbial use. Second, the analysis makes crucial use of the information structure of the utterance and offers a fully compositional account in terms of focus semantic value, literal meaning and contrast. Third, the analysis of stressable eigentlich carries over to the question case without any additional stipulations. The approach likewise allows us to speculate on the demarcation line between truth conditional and emotive uses of eigentlich and offers straightforward reasons to distinguish truth conditional uses at least from "pensive" uses at the end of the spectrum of emotive usages. Finally, the present approach could be helpful in clarifying the notions of "normally behaved" and "normally looking" exemplars of a kind, or worlds in a proposition. This could help to cut short some overgenerations inherent in Schmitz and Schröder's account.

\section{REFERENCES}

Büring, D. 2003. On D-trees, Beans, and B-accents. Linguistics and Philosophy 26(5), 511-545. 
Büring, D. 2007. Semantics, Intonation, and Information Structure. In G. Ramchand and C. Reiss (eds.), The Oxford Handbook of Linguistic Interfaces, pages 445-474, Oxford.

Eckardt, R. 1999. Normal Objects, Normal Worlds, and the Meaning of Generic Sentences. Journal of Semantics 16(3).

Eckardt, R. 2006. Dependent on context: eigentlich in adjectival and adverbial use. In C. Fabricius-Hansen, B. Behrens and M.F. Krave (eds.), Pre-Proceedings of the SPRIK Conference 2006, pages 7-11, Oslo.

Frühwirth, A. 1999. Syntax, Semantik und Pragmatik der deutschen Modalpartikel eigentlich. Marburg, mA Arbeit.

Horn, L. 2002. Uncovering the 'un'-word: A study in lexical pragmatics. Sophia Linguistica 45, 1-64.

Kohrt, M. 1988. Deutsche Sprache 2, Chapter Eigentlich, das Eigentliche und das Nicht-Eigentliche. Zum Gebrauch einer sogenannten Abtönungspartikel, pages 103-130.

Link, G. 1983. The Logical Analysis of Plural and Mass Terms: A Lattice-Theoretical Approach. In R. Bäuerle, Ch. Schwarze and A. von Stechow (eds.), Meaning, Use and Interpretation of Language, pages 302-323., Berlin: Walter de Gruyter.

Meibauer, J. 1994. Modaler Kontrast und konzeptuelle Verschiebung. Studien zur Syntax und Semantik deutscher Modalpartikeln. Tübingen: Niemeyer Verlag.

Port, A. 2006. Was heißt eigentlich eigentlich? Eine semantische und pragmatische Analyse. Masters Thesis, HU, Berlin, magisterarbeit.

Schmitz, H.-C. 2008. Eigentlich again. In A. Grønn (ed.), Proceedings of SuB 12, pages 567-581, Oslo.

Schmitz, H.-C. and Schröder, B. 2004. Sprache und Datenverarbeitung, Chapter Updates with 'eigentlich. 1-2.

Schwarzschild, R. 1999. Givenness, AvoidF and Other Constraints on the Placement of Accent. Natural Language Semantics 7(2), 141-177.

Thurmair, M. 1989. Modalpartikeln und ihre Kombinationen. Tübingen: Niemeyer.

Weydt, H. 1977. Abtönungspartikel. Die deutschen Modalwörter und ihre französischen Entsprechungen. Bad Homburg vor der Höhe: Gehlen.

Weydt, H. and Hentschel, E.l. 1983. Kleines Abtönungswörterbuch. In Partikeln und Interaktion, volume 3, Tübingen. 
AUTHOR CONTACT INFORMATION

Regine Eckardt

University of Göttingen

English Dept.

Käte-Hamburger-Weg 3

D-37073 Göttingen

Germany

regine.eckardt@phil.uni-goettingen.de 